\title{
"TODO MUNDO TÁ SEMPRE TOMANDO CONTA DA VIDA DOS OUTROS": VIVÊNCIAS E TRAJETÓRIAS LGBTQIA+ EM CONTEXTOS INTERIORANOS
}

\author{
EVERYBODY IS ALWAYS STICKING THEIR NOSES INTO OTHER \\ PEOPLE'S LIVES: LGBTQIA + EXPERIENCES AND TRAJECTORIES IN \\ SMALL TOWNS AND THE COUNTRYSIDE
}

\author{
Neil Franco ${ }^{1}$ \\ Nayara Rios Cunha Salvador ${ }^{2}$
}

\begin{abstract}
RESUMO
Com base em um referencial teórico híbrido entre teorias críticas e pós-criticas e uma metodologia de bricolagem, analisaram-se os relatos de quatro participantes LGBTQIA+ (um homem gay, uma mulher lésbica, um homem trans e uma mulher trans) no intuito de descrever e refletir sobre as vivências e trajetórias que divergem da norma socialmente imposta através da qual prevaleceria uma relação sexo-gênero-desejo, especificamente no contexto de duas cidades do interior do sul do Estado do rio de Janeiro: Rio das Flôres e Valença. Compreendemos que há processos de exclusão e violência simbólica mais proeminentes neste contexto, o que leva muitas pessoas LGBTQIA+ a procurarem os grandes centros em busca de emprego e liberdade de expressão identitária.
\end{abstract}

Palavras-chaves: Cidades interioranas. Lésbicas. Gays. Homens trans. Mulheres trans.

\begin{abstract}
Based on a hybrid theoretical framework between critical and post-critical theories and a DIY methodology, the reports of four LGBTQIA + participants (a gay man, a lesbian woman, a trans man and a trans woman) were analyzed in order to describe and reflect on the experiences and trajectories that diverge from the socially imposed norm through which there would be a sex-gender-desire relationship, specifically in the context of two cities in the interior of the south of the State of Rio de Janeiro: Rio das Flôres and Valença. We understand that there are processes of exclusion and symbolic violence that are more prominent in this context, which leads many LGBTQIA + people to look for large centers in search of employment and freedom of identity expression.
\end{abstract}

Keywords: Contryside. Lesbians. Gays. Trans men. Trans women.

\footnotetext{
${ }^{1}$ Atualmente é Professor adjunto da Universidade Federal de Juiz de Fora (UFJF), Faculdade de Educação Física e Desportos, Departamento de Ginástica e Arte Corporal. Docente do Programa de Pós-Graduação em Educação da UFJF. Doutor em Educação pela Universidade Federal de Uberlândia. e-mail: neilfranco010@ hotmail.com

${ }^{2}$ Atualmente é Professora na SEEDUC-RJ. Mestre em Educação pela Universidade Federal de Juiz de Fora UFJF. e-mail: nayara616@yahoo.com.br
} 


\section{O PANORAMA: PALAVRAS INICIAIS}

A vida anda diferente. Não é apenas pela pandemia ou pelo isolamento social, necessário à sobrevivência, mas impossível a todas as pessoas no Brasil, mas principalmente pelo contexto político de nosso país. Há um flerte evidente com o fascismo e uma volta a enquadramentos moralistas e normativos, que outrora mantiveram tantas pessoas lésbicas, Gays, Bissexuais, Trans ${ }^{3}$, Queer, Intersexo, Agêneros, Assexuados (e mais) e outras possibilidades identitárias (LGBTQIA+) "no armário".

É nesse ambiente de "ar rarefeito" que escrevemos sobre vivências e trajetórias de sujeitos dissidentes das vivências do gênero e sexualidades, marcadas pelas especificidades do contexto interiorano de duas cidades vizinhas; ambas no interior do Estado do Rio de Janeiro, mais especificamente no sul do estado, a saber: Rio das Flôres e Valença.

Essa escrita diz sobre um posicionamento político e identitário; uma escrita que demonstra detalhes e angústias relacionadas à subjetividade de pessoas LGBTQIA+ num contexto interiorano e com características rurais, em que pessoas vítimas do machismo, da homofobia e da transfobia, passam por constrangimentos de forma pública, uma vez que, conforme demonstra o título deste trabalho, excerto da fala de uma das participantes entrevistadas, "como as pessoas conhecem você e sua família, todo mundo tá sempre tomando conta de tudo e de todo mundo" (Juliana, 36 anos; junho de 2020).

A partir de uma aproximação teórica entre teorias críticas e pós-críticas, buscamos compreender como os processos de construção identitária e subjetiva de pessoas LGBTQIA+ são atravessados pelas compreensões sociais e culturais acerca da construção do gênero e vivências de sexualidades dissidentes existentes em contextos interioranos e rurais.

Antes de adentrarmos às discussões teóricas sobre este trabalho, é preciso elaborar melhor alguns conceitos e raciocínios que serão necessários para a compreensão de passagens do texto e escolhas epistemológicas aqui presentes.

\footnotetext{
${ }^{3}$ Optamos pelo termo pessoas trans conforme utilizado em pesquisas anteriores (BENEDETTI, 2005), para nos referirmos a todas as pessoas que divergem da norma binária de gênero, sejam elas transexuais, travestis ou transgêneras.
} 
Em primeiro lugar, trata-se da dita aproximação teórica entre teorias críticas e póscríticas, através do que hoje, convenciona-se chamar de marxismo queer. Essa opção teórica, relativamente nova, será melhor apresentada no tópico sobre metodologia. Porém, cabe aqui indicar que essa escolha parte de uma compreensão que a fragmentação dessas duas perspectivas traz mais malefícios do que vantagens à pesquisa. Deve-se, ainda, ao entendimento de que, guardados certos exageros teóricos e extremamente ortodoxos, há a possibilidade e, mais que isso, a necessidade de uma releitura e reaproximação de aspectos teóricos estruturalistas e pós-estruturalistas, para uma devida análise sociológica que possa ser, também, aberta às questões subjetivas dos indivíduos.

Em segundo lugar, é interessante deixarmos claro o que significa a sigla LGBTQIA+ aqui utilizada e como se compreendem, a partir de certos argumentos teóricos, as categorias de gênero e sexualidade. Segundo Guilherme Bortoletto (2019), a sigla citada refere-se às pessoas que não se enquadram numa perspectiva normativa tanto de sua orientação (ou identidade) sexual como de sua identidade de gênero. Assim, trata-se de pessoas que identificam-se como lésbicas, gays, bissexuais, transexuais, travestis e transgêneros, queer, intersexo, agêneros, assexuados e mais.

Quanto às perspectivas de gênero e sexualidade, podemos afirmar, por ora e de forma simplificada, que o gênero parte de uma questão de identificação com formas de ser e sentirse homem, mulher, ambos ou nenhum (FRANCO, 2019), enquanto a sexualidade diz respeito ao interesse sexual, a afeto e fantasias, de modo que a pessoa pode sentir-se sexualmente interessada por outras ou não sentir interesse ou desejar investimentos afetivos (BRASIL, 2009).

Dadas estas delimitações teóricas e conceituais, seguimos, agora à base teórica deste artigo e, posteriormente à sua metodologia e análise dos dados produzidos através das entrevistas. 


\section{CORPOS QUE IMPORTAM (?): identidades LGBTQIA+}

Movemos-nos, neste tópico, a refletir, através das bases teóricas anunciadas, acerca das identidades LGBTQIA+ a partir da correlação das bases teóricas anteriormente anunciadas, no sentido de mobilizar a articulação necessária entre teoria e prática social de enfrentamento ao sexismo, à homofobia, à transfobia e a toda e qualquer forma de preconceito, e, ainda, para trazer a consistência teórica necessária à análise das falas provenientes das entrevistas feitas.

O conceito de identidade foi discutido por diversas/os autoras/es, de diferentes formas. Entre elas/es, baseamo-nos nos escritos de Tomaz Tadeu da Silva (2000), para quem as identidades são formadas simbólica e socialmente e cuja luta por afirmação tem causas e consequências materiais. $\mathrm{O}$ autor enfatiza, ainda, que a diferença é uma marca da constituição identitária dos sujeitos, sendo, ainda, histórica e localizada, passando, muitas vezes, por conflitos.

O autor relata, ainda, que a discussão do conceito de identidade é importante para desfazer essencialismos, como por exemplo, a noção de que a identidade de gênero e sexual têm base unicamente biológica; o mesmo pode-se dizer a respeito da construção social acerca da maternidade, de modo que o essencialismo se demonstra de diferentes formas.

Numa perspectiva materialista histórico-dialética em articulação com os Estudos Culturais, há de se considerar não apenas a constituição subjetiva das identidades, mas as relações de poder e as desigualdades sociais e políticas que envolvem tal constituição na sociedade capitalista. Desse modo, a reflexão acerca das identidades faz-se importante para articular sentimentos e reivindicações de pertencimento, que podem tornar-se agências de luta contra noções hegemônicas e formas de opressão e dominação tais como o patriarcado como determinante nas relações de gênero, a colonialidade, a subalternidade de certos grupos sociais, o capitalismo, o racismo, etc. na estrutura e nas relações de produção (ENNES; MARCON, 2014). 
Assim, há de se refletir sobre a indissociabilidade existente em todas as formações identitárias, dos marcadores de gênero, raça e classe de modo que pessoas são marginalizadas em razão desses marcadores sociais que "[...] operam segundo as necessidades e conveniências do sistema produtivo de bens e serviços, assumindo diferentes feições de acordo com a fase de desenvolvimento do tipo estrutural da sociedade." (SAFFIOTI, 2013, p. $60)$.

No que diz respeito às identidades LGBTQIA+, devemos compreender as diferenças (geralmente imbricadas) entre gênero e sexualidade e, lembrar sempre, que tais marcadores sociais não operam de forma isolada, mas sempre articulada a outros marcadores, conforme elucidado por Heleieth Saffioti (2013).

Compreende-se o gênero como uma construção social, material e discursiva, desenvolvida de forma diferente em tempos e culturas distintas, e que diz respeito à constituição normativa das categorias homem e mulher. Segundo Letícia Lanz (2014, p. 39), trata-se das "expectativas sociais de desempenho que cada ser humano deve atender tendo em vista o seu sexo genital".

Os estudos de Judith Butler (2004) apontam o gênero como uma norma social incorporada nas/os atoras/es e que permite que certos tipos de práticas e ações tornem-se legitimadas e inteligíveis, enquanto outras são simplesmente invisibilizadas, de modo que tal norma é capaz de eleger os parâmetros do que aparecerá e do que desaparecerá dentro da esfera social. É, ainda, um aparato de normalização do que é considerado feminino ou masculino.

Entendido tal sentido, compreende-se que a identidade de gênero se constrói com base em tal norma, mesmo que seja no sentido de desestruturá-la, contestar sua naturalidade aparente e construída, de modo que as pessoas possam identificar-se como homens ou mulheres, ou ainda, com uma fluidez entre ambos ou nenhum dos dois, fragmentando, dessa maneira, o dispositivo binário do gênero. 
Com relação à sexualidade, ocorre, da mesma maneira, uma naturalização por meio de práticas discursivas, sociais e históricas, que também instituem algumas formas de afetividade e desejo como naturais e relacionadas a aspectos biológicos. Desse modo, há uma universalização da noção de que a sexualidade "natural" seria vivida entre parceiros de gênero oposto; concepção fortemente descrita por teóricos/as pós-críticos/as como a "heteronormatividade". Para que essa naturalização se mantenha, há uma série de dispositivos e tecnologias de poder e normalização que são praticadas na e pela sociedade. Conforme aponta Michel Foucault (1988, p. 80): "O poder seria, essencialmente, aquilo que dita a lei, no que diz respeito ao sexo. O que significa, em primeiro lugar, que o sexo fica reduzido, por ele, a regime binário: lícito e ilícito, permitido e proibido".

Há, dessa maneira, uma tentativa de "reinserção ao armário", uma busca em fazer com que as pessoas que dirigem seu afeto a outras, do mesmo gênero sejam consideradas anormais. Muitas vezes, tais discursos, quando não conseguem defender um essencialismo baseado em aspectos biológicos, se embasam em perspectivas religiosas, sob as quais se busca legitimar o que deve ser considerado certo ou errado, o que é pecado e o que é "possível" nos preceitos defendidos por esta ou aquela religião, propondo um código moral a ser seguido (CASTRO; FERRARI; 2017).

Outra forma de poder que se "apossa" da heteronormatividade para se manter e se perpetuar, é o patriarcado. Imbricado nas relações capitalistas, o patriarcado mobiliza discursos e ações contra a comunidade LGBTQIA+ e a liberdade sexual das mulheres, pois precisa manter a estrutura da família burguesa heterocentrada para garantir a reprodução econômica e social (SOF, 2016)

Há, ainda, outros dispositivos e instituições que reproduzem e perpetuam a heteronormatividade, silenciando, docilizando e impedindo a vivência plena das pessoas, conforme suas identidades de gênero e sexualidade. Destacamos, nesse sentido, a escola, como um local cujas práticas e arquitetura reforçam a heteronormatividade e invisibilizam, silenciam e excluem pessoas que rompem com a binaridade de gênero e as normas heterossexuais construídas ao longo dos anos (LOURO, 1997). 
É importante ressaltar que as discussões trazidas aqui são uma introdução teórica para as análises empreendidas através dos relatos provenientes das entrevistas, de modo que outras/os atoras/es além dos que aqui foram referenciadas/os, estarão presentes, para dar corpo às análises das falas trazidas neste trabalho.

O que nos resta indagar, neste momento, é como essas relações se estreitam ou se diferenciam em contextos de interior, reflexão que passamos a fazer, neste momento.

\section{CIDADEZINHAS DE INTERIOR: ASPECTOS GEOGRÁFICOS E SOCIOLÓGICOS DA PESQUISA}

As cidades interioranas relatadas nesta pesquisa são vizinhas. Ambas situam-se no sul do estado do Rio de Janeiro, numa região conhecida como Médio Paraíba, e fizeram parte do que é historicamente conhecido como "ciclo do café". Rio das Flôres e Valença são muitas vezes chamadas pelos munícipes de "cidades irmãs", não apenas por sua proximidade, mas porque consistiam de uma única cidade no passado. Rio das Flôres pertenceu à cidade de Valença de 1815 a 1890, quando foi desmembrada e, mais tarde, em 1929, elevada à categoria de cidade (IBGE, 2017).

O ciclo do café fez com que as duas cidades, durante o período da economia cafeeira, tivessem bastante poder econômico e a herança deste período ainda pode ser vista nas construções e nas diversas fazendas existentes na região, fazendas essas que hoje, em sua maioria foram transformadas em equipamentos turísticos ou hotéis-fazenda, uma vez que as mudanças na economia e a decadência da produção de café e, posteriormente, pecuária leiteira, assim o demandaram (SILVA, 2013).

Assim como em diversas cidades de interior, devido à grande influência da igreja católica, o centro das duas cidades cresceu em torno da igreja, que ocupa lugar de destaque na arquitetura local (SILVA, 2013).

Rio das Flôres tem uma população estimada de 9284 pessoas e uma densidade demográfica de 17,90 habitantes por quilômetro quadrado, sendo a $88^{\text {a }}$ (octogésima oitava) 
cidade no ranking populacional, entre as 92 do estado. Ainda hoje, sua economia é fortemente baseada em atividades agrícolas e pecuárias (IBGE, 2017). O município não tem muitos equipamentos culturais, contando com uma biblioteca pública municipal, uma casa de cultura e um parque de eventos. Não há museu, teatro ou cinema na cidade (RIO DE JANEIRO, 2011).

Resumidamente, a cidade guarda características rurais em harmonia com alguns aspectos mais urbanos, na arquitetura e em seu pequeno centro comercial. Muitas pessoas ainda vivem em localidades isoladas do centro da cidade, em fazendas ou sítios, com economia rural e sem acesso à telefonia a internet. A cidade guarda, ainda, costumes bastante interioranos como quermesses e procissões, o que demonstra uma tradição católica ainda bastante forte no município, que também conta com igrejas evangélicas e centros espíritas e de candomblé e umbanda, porém, essas duas últimas matrizes religiosas ainda não são "publicamente" reconhecidas ou valorizadas. A cidade tem, também, uma conhecida festividade e tradição de folia de reis, que ocorre a cada ano, na Praça de Santos reis, em Manuel Duarte, distrito de Rio das Flôres.

De maneira geral, pode-se afirmar que o passado "coronelista" deixou marcas na cidade, ainda fortemente marcadas por ideologias machistas, racistas, patriarcais e LGBTfóbicas. Dado o contexto demográfico citado no início desta apresentação sobre a cidade, pode-se afirmar que, no caso de Rio das Flôres, "sair do armário" e assumir sua identidade sexual ou de gênero não é uma atitude que se dá apenas no âmbito particular e familiar dos sujeitos. Como a cidade é muito pequena, todos se conhecem, de modo que tal decisão e reivindicação identitária torna-se uma experiência partilhada e, mais que isso, um evento público, que se torna "notícia" em toda a cidade.

De maneira muito parecida se dão as mesmas questões em Valença, cidade vizinha. O que diferencia primordialmente as duas cidades é o tamanho, o nível de urbanização e comércio e a densidade demográfica.

Valença, assim como Rio das Flôres, passou por um grande desenvolvimento e opulência à época da cultura do café, tendo que, posteriormente mudar suas atividades 
econômicas quando da decadência da produção cafeeira, passando a desenvolver-se através da indústria têxtil, ainda existente na cidade, mas não com a mesma força dos anos 40 e 50 (período de instalação deste tipo de indústria no município). Hoje, a cidade, com população estimada de 76.523 habitantes e densidade demográfica de 55,06 habitantes por quilômetro, conta com um comércio bastante estruturado, com um centro universitário (que traz muitas/os estudantes de outros locais para a cidade). Ainda assim, é possível encontrar na cidade questões que não ocorrem em grandes centros, como grande importância a nomes de "grandes famílias", o fato de grande parte das pessoas se conhecerem e os lugarejos rurais que compõem a cidade e por vezes atravessam seu centro, misturando características urbanas e rurais no mesmo espaço-tempo (PIÑEROS, 2015).

\subsection{Pessoas LGBTQIA+ em cidades de interior}

O que pode-se dizer, com relação às duas cidades, é que elas formam aquilo que se denomina continuum rural-urbano, que, segundo Maria Encarnação Sposito (2010, p. 121), caracteriza-se por "zonas de transição entre esses espaços pelo compartilhamento, no mesmo território ou em micro parcelas territoriais justapostas e sobrepostas, de usos do solo, de práticas socioespaciais e de interesses políticos e econômicos associados ao mundo rural e ao urbano".

Assim como já relatado neste trabalho, essas cidades apresentam características que se diferenciam bastante dos grandes centros no que diz respeito ao acesso cultural e de lazer e ás formas de interação e de vida. Nessas cidades, as atividades são ainda mais grupais, as crianças ainda brincam nas ruas e o tempo parece passar mais devagar, já que não há trânsito e nem correria no dia-a-dia. Tudo é perto, tudo se faz a pé. Para se ter uma ideia, na cidade de Rio das Flôres, por exemplo, não há semáforo e nenhum prédio (todos com poucos andares) tem elevador ou escada rolante. Além disso, os processos de subjetivação se dão de forma diferente, como afirma João Lopes (2000, p. 85):

Às cidades de pequena dimensão faltam limiares mínimos de oferta e de procura, economias de escala, diversificação e especialização de mercados (tão necessários à 


\section{Revista \\ Debates Insubmissos}

acumulação flexível e ao ciclo breve dos produtos num contexto produtivo pósfordista), bem como um universo de valores e práticas centrados na procura de consumos culturais mundanos e em estratégias auto-identitárias, de apresentação de si e de valorização de estilos de vida próprios de um individualismo expressivo e relacional.

Assim, dadas as características dessas cidades e as relações de poder que nelas se inserem, assumir uma identidade sexual ou de gênero diferente da norma socialmente aceita, é um desafio. Segundo Anderson Ferrari e José Gabriel Barbosa (2014, p. 214): "ser homossexual, assumir ou não a homossexualidade na cidade do interior é bem diferente do que ocorre numa cidade grande". Os autores apontam, ainda que em cidades de interior, a homossexualidade é exercida, mas não pronunciada e não debatida publicamente e que as identidades que não correspondem à ordem heteronormativa sofrem processos restritivos mais potencializados.

Outro, dos diversos achados desta pesquisa acima destacada é que, em cidades pequenas e mais conservadoras, os relacionamentos entre pessoas do mesmo gênero tendem a ser mais efêmeros e clandestinos, dada a vigilância e interdição mais constantes nessas localidades. Partindo desses achados prévios provenientes da escassa literatura disponível acerca do tema em questão, apresentamos a metodologia e os resultados desta pesquisa, bem como as análises das falas, dadas em contexto com as bases teóricas aqui evidenciadas.

\section{METODOLOGIA}

Conforme já anunciado na introdução deste trabalho, partimos de uma perspectiva teórica que busca fazer uma costura entre diversos pontos de vista, considerando-os como complementares. Deste modo, no que se refere à base teórica, aproximamo-nos do que se convencionou chamar de marxismo queer, perspectiva que busca alinhar as reflexões acerca de classe, raça e gênero de forma a serem compreendidas como inseparáveis.

Os estudos sobre gênero e sexualidade geralmente se dão numa perspectiva das teorias pós-críticas, que de acordo com Silva (1993), negam as explicações universais e as totalidades ou completudes, optando por narrativas parciais, e pelas particularidades e localidades. 


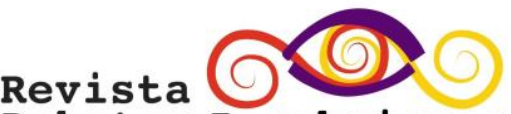 \\ Debates Insubmissos}

Acreditamos, porém, que não se formam identidades e subjetividades que não pertençam, ao mesmo tempo, a relações de poder micro e macro-estruturadas. Assim, não descartamos a necessidade e o uso de conceitos das teorias críticas e das teorizações feministas materialistas, juntamente com aspectos das teorias pós-críticas, principalmente da teoria queer, para a compreensão das estruturas sociais que se mantém ainda existentes no mundo capitalista, racista e patriarcal, e que contribuem para a forma como vivemos e interagimos, bem como para a inteligibilidade das noções de raça, classe e gênero, como categorias imbricadas, consubstanciadas e que permitem análises sociológicas de uma perspectiva mais totalizante da sociedade, que não pode ser descartada em vista apenas das questões culturais ou identitárias. Desse modo, recorremos ao materialismo e não tão somente às análises pós-estruturalistas, ao compreender que:

Para resumir a perspectiva materialista, considerar a sexualidade apenas sob o aspecto das práticas e transformá-la em um campo de estudos ou de luta autônoma, fora de qualquer contexto histórico e social, é correr o risco de ocultar as relações sociais que a organizam e fazem dela alguma coisa muito diferente, segundo a posição de sexo (mas também de classe e de raça) que cada pessoa ocupa (FALQUET, 2019, p. 136)

Assim, pode-se dizer que nos aproximamos em perspectiva teórica do que tem sido chamado ultimamente de marxismo queer, ou seja, uma "virada (ou giro) materialista" que busca articular queer e materialismo, feminismo materialista e queer, etc. (ABREU; CASTRO, 2019). Ou seja, pretende-se, aqui articular às questões sobre identidade, o necessário debate sobre desigualdades de classe e os aspectos materiais da dominação.

Ainda sobre as análises e o modo de investigação empreendidos neste artigo, optamos pela bricolagem, como método investigativo que busca incorporar diferentes pontos de vista a respeito de um mesmo fenômeno, utilizando-se diversas perspectiva teórico-investigativas presentes na sociedade atual, sem desconsiderar as relações de poder presentes no cotidiano (KINCHELOE, 2007).

Com relação aos instrumentos de produção de dados e aproximação dos participantes, há algumas especificações também a serem feitas. A produção dos dados se deu através de entrevistas com 04 participantes, sendo 02 de identidade de gênero divergente da norma social 
imposta, mas que têm relações afetivas orientadas na heterossexualidade (um homem e uma mulheres trans) e 02 participantes cuja identidade sexual não segue os padrões heteronormativos, mas cujas identidades de gênero se enquadram na norma cisgênera ${ }^{4}(01$ homem gay e uma mulher lésbica). Todas/os as/os participantes têm maioridade, estando suas idades expressas nos relatos de suas respectivas entrevistas.

Algumas/uns das/os participantes que foram aqui entrevistadas/os, já haviam participado de uma pesquisa de mestrado por nós concluída sobre os processos educativos de pessoas trans do interior do Rio de Janeiro, novamente convidadas/os a responderem as questões que deram origem a este artigo. A partir deste convite, a pesquisadora pediu que as/os mesmas/os indicassem outras pessoas que pudessem ser entrevistadas no contexto das duas cidades em questão, sendo este tipo de execução de amostragem denominada bola de neve:

A execução da amostragem em bola de neve se constrói da seguinte maneira: para o pontapé inicial, lança-se mão de documentos e/ou informantes-chaves, nomeados como sementes, a fim de localizar algumas pessoas com o perfil necessário para a pesquisa, dentro da população geral. Isso acontece porque uma amostra probabilística inicial é impossível ou impraticável, e assim as sementes ajudam o pesquisador a iniciar seus contatos e a tatear o grupo a ser pesquisado (VINUTO, 2014).

Após a aproximação, o contato com aquelas/es que decidiram participar da entrevista, foi feito por aplicativo de conversa (whatsapp) no período de 15 a 22 de junho de 2020. As entrevistas foram feitas em formato de áudio, em tom de conversa. A pergunta principal que norteou a entrevista foi: "Como é ser LGBTQIA+ em uma cidade de interior?", seguida de perguntas complementares, como por exemplo, se a pessoa já morou em grandes centros e quais as diferenças poderia apontar no tratamento das pessoas e na vivência.

Para garantir a segurança e integridade dos sujeitos e para que os mesmos não sejam expostos a nenhum tipo de risco ou inconveniente, suas identidades foram preservadas e optamos pelo uso de nomes fictícios.

\footnotetext{
${ }^{4}$ Refere-se à norma que estabelece uma relação entre a identidade de gênero e o sexo biológico. Entende-se como cisgênera, a pessoa se identifica com o gênero que lhe foi determinado quando de seu nascimento (JESUS, 2012).
} 


\section{SERES E VIVERES LGBTQIA+ NO CONTEXTO INTERIORANO E/OU RURAL}

Para as análises abaixo empreendidas, anunciaremos a pergunta feita pela entrevistadora, seguida das respostas e as reflexões acerca das mesmas. Iniciaremos então, seguindo a ordem da siga LGBTQIA+, com os dados referentes à entrevista feita com Juliana $^{5}$, mulher lésbica de 36 anos, casada, enfermeira, residente na cidade de Rio das Flôres.

A primeira pergunta feita à Juliana foi sobre como é ser lésbica numa cidade de interior e tão pequena.

A participante começou seu relato falando sobre sua condição familiar hoje. Ela é casada e sua esposa vive o primeiro relacionamento homoafetivo, desse modo, Juliana assumiu também a maternidade dos três filhos de sua companheira, frutos de relacionamentos anteriores. Em seguida, Juliana relatou que de todas as dificuldades que passou na cidade, os momentos mais difíceis foram na adolescência, quando ainda dependia da família e não tinha condições financeiras de se manter sem essa ajuda. Para ela, a fase da descoberta da lesbianidade no contexto de interior não foi fácil:

É uma fase muito difícil, ainda mais numa cidade de interior, porque todo mundo conhece todo mundo; todo mundo tá sempre tomando conta da vida dos outros... então foi uma fase muito difícil da minha vida. Eu tive depressão (....). Foi muito complicado, foi muito sofrido, foi muito doloroso (JULIANA, 36, Junho de 2020).

Este primeiro excerto da fala de Juliana já diz muito sobre esse poder panóptipo (FOUCAULT, 1999) extremamente presente nas cidades pequenas, pelo fato de que todas/os se conhecem. Esses corpos conhecidos passam a ser vigiados, pois uma vez conhecidos sua existência é mais material naquele contexto. Não se trata de uma referência a uma lésbica, uma foto ou alguém na TV. Não é uma desconhecida. É uma pessoa com quem a convivência se dá nas relações do cotidiano, o que parece abrir maior espaço para tal vigilância e interdição.

Juliana relata muitas dificuldades em sua própria aceitação e na aceitação familiar num primeiro momento, e da vontade de sair de sua cidade para, nos relatou, "colocar para fora

\footnotetext{
${ }^{5}$ Todos os nomes são fictícios, para que a identidade das/os participantes seja preservada.
} 


\section{Revista \\ Debates Insubmissos}

aquilo que ela realmente queria ser." Ela destaca ainda sobre os comentários acerca de sua expressão corporal e de gênero, na escola:

Você está ali e as pessoas falam: 'mas, parece um homem' (...) tem sempre alguém
falando do seu jeito de ser, da forma que você é (...) os colegas com apelidos tipo
'moleque-macho' e coisas do tipo, que eu já ouvi muito e são muito ofensivos. Aí
você não quer chamar atenção, mas de certa forma, acaba chamando (JULIANA,36,
junho 2020).

A fala de Juliana demonstra que as interdições sobre a mulher lésbica se intensificam quando sua expressão corporal e de gênero foge aos padrões de feminilidade esperados pela sociedade. Esse relato diz sobre os discursos que, como apontam Foucault (1988) e Butler (2004) estabelecem o que pode ou não pode ser aceito ou legitimado quando se trata das identidades sexuais e de gênero.

Juliana continua sua fala dizendo que na cidade pequena, tudo tem que ser escondido:

Quando você se apaixona por alguém do mesmo sexo que você, aqui, tudo é mais complicado, porque todo mundo te conhece, então ninguém pode descobrir, porque sua mãe não pode saber isso é muito tenso. Você não tem lugares pra viver isso, é tudo escondido. Fora, você sempre tem as boates, as paradas (...). A gente tem um pouco mais de liberdade. Por isso, eu fui criar minha independência, parti, fui trabalhar, fui morar fora (JULIANA, 36, junho 2020).

A decisão de sair da cidade e do âmbito familiar resulta, provavelmente, de questões relacionadas ao que Eve Sedgwick (2007) nomeou como epistemologia do armário. A autora relata que o armário homossexual não abriga apenas a pessoa, mas diversas outras instâncias, como a família, amigos, trabalho. Assim, talvez Juliana tenha preferido se afastar, mantendo no armário questões familiares e a falta de oportunidade de emprego para pessoas LGBTQIA+ na cidade e afastando-se, para poder, sozinha, se libertar, como ela mesma disse.

O relato de Juliana também indica a dinâmica de cidade pequena em que as notícias "se espalham como rastro de pólvora", ou seja, caso alguém soubesse de suas lesbianidade, seria certo que sua mãe também acabaria descobrindo e a família seria arrancada de seu armário. A saída da cidade preocupou Juliana pelas notícias e relatos de violência e morte de pessoas LGBTQIA+, no entanto, ela relata que:

Graças a Deus eu sofri muito pouco preconceito fora da minha cidade, fui sempre muito bem recebida, na minha profissão, com todo mundo que eu trabalhei (...), 


\section{novistet \\ Debates Insubmissos}

claro que já tive momentos de ser ofendida, inclusive por pacientes, mas não foi tanto assim (JULIANA,36, junho 2020).

A entrevistada dá indícios de que, mesmo tendo sofrido algum tipo de preconceito e lesbofobia no contexto de um grande centro, não chegou a ser tão forte quanto às vivências que teve em sua cidade. Ela conta, porém, que depois de ter conquistado sua liberdade, ela decidiu voltar.

Depois de ter alcançado minha liberdade eu decidi voltar para minha cidade. Hoje, sim, eu sou uma pessoa muito bem resolvida, casada, com minha família, minha esposa, meus filhos, minha bebezinha que eu crio desde que ela nasceu (...). Mas isso aqui foi muito difícil também, porque uma mulher com três filhos viver com outra mulher (...) a gente passou por muita coisa, mas a gente superou. Pra mim, foi até mais complicado que pra ela, porque eu já tinha aquela coisa de as pessoas estarem sempre falando, sempre comentando e você vive a sua vida todinha nessa de aceitação, a gente acha que quando a gente se aceita a sociedade também vai aceitar (...), mas no começo foi difícil, eram muitos comentários (JULIANA,36, junho 2020)

As falas de Juliana indicam que o fato de as pessoas se conhecerem e comentarem umas com as outras sobre as vivências sexuais de pessoas LGBTQIA+ é incômodo, sendo um processo que atravessa a subjetividade dessas pessoas de forma diferente no contexto de interior e cidade pequena, reforçando a afirmação de Ferrari e Barbosa (2014) de que nessas cidades o processo de vigilância e interdição dos corpos é mais intenso. Além disso, há ainda a observação acerca da vigilância da vida de sua esposa.

Juliana demonstra que numa cidade pequena, não é aceitável que uma mulher, que antes se compreendia heterossexual e tem filhas/os, passe a viver com outra mulher, o que dá indícios de que não apenas a lesbofobia está presente na cidade, mas também as relações machistas e patriarcais que recaem sobre todas as mulheres. Segundo Maria Luiza Heilborn (1999, p. 77) os modos de viver a sexualidade numa sociedade patriarcal são modelados, de modo que as vivências sexuais são "enquadradas por um conjunto de leis, costumes, regras e normas variáveis no tempo e no espaço".

Dando continuidade e para finalizar a entrevista, perguntamos à entrevistada quais as principais diferenças que ela via de uma cidade pequena para um grande centro em sua trajetória como lésbica. Ela relatou, conforme já havia feito: 


\section{novist

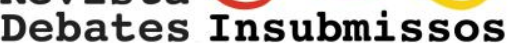

É muito diferente, é aquilo que eu te falei, ainda dá medo de beijar na rua por causa da violência na cidade grande, mas sempre, em toda cidade grande tem um canto GLS (...). A diferença da cidade grande é que a agressão física lá é mais fácil de acontecer. Aqui a gente tem segurança, porque aqui não tem caso de violência, mas por ser cidade pequena a gente não faz, a gente não mostra (JULIANA, 36, junho 2020).

O último relato de Juliana diz de um processo de fiscalização da sexualidade que se dá nos dois espaços, mas de formas diferentes. Na cidade grande, o medo da violência física proveniente da lesbofobia, mas a possibilidade de, em lugares específicos, viver a sexualidade de forma mais livre, enquanto no interior, apesar da não violência, essas vivências são mais interditas de forma simbólica, no sentido da vigilância panóptipa e do disciplinamento (FOUCAULT, 1999).

Seguiremos, agora, ao segundo entrevistado, um homem gay de 22 anos, estudante, que vive num pequeno distrito da cidade de Rio das Flôres, chamado Manuel Duarte. Ele será chamado de Lucca. A entrevista teve a mesma estruturação anterior, ou seja, partimos da pergunta: como é ser gay numa cidade de interior e tão pequena? Ao ouvir a pergunta, Lucca respondeu:

Ih é complicado! Eu me assumi aos 18 anos para toda a família, na verdade para a cidade toda né, por ser tão pequena, os boatos correram rápido. Ainda para melhorar, fui o primeiro garoto gay a aparecer com seu namorado aqui em Manuel Duarte. Não foi nada fácil no início, porque por mais que já existissem gays aqui, foi a primeira vez que eles viram um relacionamento homoafetivo de perto, e isso foi chocante para a minha cidade, pois todos eles me conhecem desde o nascimento e acompanharam o meu crescimento, e aqui é uma cidade de pessoas mais velhas onde a criação deles foi diferente da minha, onde a visão de relacionamento não é a mesma (LUCCA, 22 anos, junho 2020).

Este primeiro relato de Lucca já aponta semelhanças importantes com a pesquisa de Ferrari e Barbosa (2014) e com os relatos de Juliana. Tais semelhanças indicam que um dos fatos importantes na construção identitária e na subjetividade de pessoas LGBTQIA+ nas cidades do interior tem relação com os "boatos", o fato de que as notícias chegam rapidamente a todos os cantos e, por todas/os se conhecerem, isso torna a "saída do armário" mais difícil. Outro fato presente na pesquisa de Ferrari e Barbosa (2014) no contexto da cidade de Leopoldina (MG) e corroborado pela fala de Lucca é que em cidades interioranas e pequenas, os relacionamentos homoafetivos são efêmeros e clandestinos. Talvez por isso, 


\section{Revista \\ Debates Insubmissos}

apesar da existência desses relacionamentos, a aparição pública do rapaz com o namorado tenha causado tanto choque, porque trouxe à materialidade aquilo que só existia nos discursos, nos comentários, nos "burburinhos"; o que existia, mas como ninguém via, não era público, não causava incômodo.

Outro fato importante na fala de Lucca é a noção que ele traz sobre valor geracional. Ao apontar que é "uma cidade de pessoas mais velhas com uma criação diferente", Lucca demonstra que os entendimentos acerca de questões sociais se dão numa relação os momentos históricos e a cultura e tendem a se manter, nas estruturas sociais. Ou seja, hoje os valores estão diferentes, mas para aquelas pessoas, ainda vale o que elas aprenderam, numa perspectiva mais moralista e de valores arraigados no que se compreendia como família há alguns anos.

Essa percepção da realidade baseada em preceitos moralistas e em nome da "família" aparece claramente quando Lucca diz:

(...) lembro que uma vez estava em uma praça perto de uma lanchonete com o meu ex, naquela época ainda namorado, onde nós fomos expulsos dali por conta de um beijo que demos e o dono do estabelecimento chegou gritando e falando que ali não era lugar de safadeza e que ali era um lugar de família, que se não saíssemos ele iria chamar a polícia (LUCCA, 22, junho 2020).

Esse acontecimento remete ao que Richard Miskolci (2012) nomeou como terrorismo cultural em que somos criadas/os e inseridas/os. Ou seja, uma lógica de imposição de normas que se dá sempre com a violência à espreita. Os gritos, a ameaça e o tratamento do afeto homoafetivo como crime estão expostos neste episódio. Segundo Miskolci (2012) no âmbito do terrorismo cultural a violência é acionada como forma de imposição da heterossexulaidade compulsória, mas nunca se sabe de onde ou que quem partirá essa violência, o que faz com que muitas pessoas LGBTQIA+ tenham medo de expressar afeto em público, como relatou, anteriormente a participante Juliana e como está claramente demonstrado no relato de Lucca.

Perguntei ao participante como foi depois desse acontecimento. Ele respondeu:

Em questão de "aceitação" pra uma cidade pequena foi normal, ou seja, ninguém sabia lidar com essa situação, digo isso, pois, fugia do conhecimento deles algo tão diferente assim, eles não foram criados vendo isso, então eles demoraram a se 


\title{
novist \\ 政
}

adaptar com essa nova realidade onde dois garotos estavam namorando (LUCCA, 22, junho 2020).

Lucca parece racionalizar o fato de que as pessoas não aceitem um casal homoafetivo publicamente, como se não fosse culpa delas, com o argumento de "elas não foram criadas vendo isso". A racionalização, segundo Terry Eagleton (1997), faz parte da construção das ideologias. É uma forma de convencimento ou autoconvencimento para situações ou comportamentos sociais que podem ser alvos de crítica; ou para que as condições de vida sejam mais toleráveis.

Por fim, perguntamos se ele já havia visitado ou morado em algum grande centro e quais as diferenças que percebia em relação ao interior. A resposta foi a seguinte:

\begin{abstract}
Quando eu fui morar no Rio de Janeiro, eu não tinha medo de dar as mãos para outro garoto, então eu comecei a me relacionar com um menino que sempre morou lá, e foi uma outra luta porque eu não tinha medo de demonstrar carinho na frente de outras pessoas e já ele tinha muito medo. Perguntei o porque de tanto medo e ele falou que a covardia naquela cidade era maior, que os gays eram mortos apenas por se abraçarem, ou darem um beijo. Ele chegou a pedir pra mim que a gente evitasse demonstrar afeto nas ruas por conta dessa violência. Em cidades grandes eu vi mais lutas em relação a conquistar esse espaço, onde as pessoas te respeitem por você ser quem é. Vi um número maior de gays, ou seja, de pessoas como eu. Achei incrível! Achei mais incrível eles lutando pela sua liberdade, que é a de andar com seu parceiro e poder demonstrar afeto na frente de outras pessoas, apesar de que a violência era mais constante e mais brutal a pessoas como eu. Achei tão legal ver tantas pessoas lutando por isso, as gays que eu conheci lá tinham medo, mas nunca tiveram medo de ser quem são (LUCCA,22, junho 2020).
\end{abstract}

Não é preciso dizer que este relato é muito similar ao de Juliana no que diz respeito à comparação entre cidades grandes e cidades pequenas. $\mathrm{O}$ que isso parece informar é que nas cidades grandes, as pessoas não têm medo de ser quem são e sim de seu afeto gerar violência, ao passo que em cidades pequenas, a própria identidade LGBTQIA+ é rejeitada e, nesse sentido, assumir-se LGBTQIA+ nessas localidades é resistência, é ato político. A liberdade possível em cidades grandes é cerceada pela violência homofóbica de alguns, ao passo que a violência simbólica nas cidades pequenas é tão forte, que as pessoas acabam se mudando ou viajando para assumir e viver sua sexualidade, sem a vigilância constante das cidades em que "todo mundo se conhece e toma conta da vida dos outros". 
Terminada esta entrevista, apresentamos, então os dados provenientes das conversas com 02 pessoas trans. Primeiro, uma mulher trans, de 30 anos de idade, a quem chamaremos de Flora, que viveu por muitos anos de Rio das Flôres, mas hoje vive em Volta Redonda (RJ), retornando a Rio das Flôres apenas alguns finais de semana para visitar sua família e amigos.

Partindo da mesma pergunta, sobre como é ser trans numa cidade pequena, Flora respondeu:

Eu fiz minha transição aí em Rio das Flôres, ainda menor de idade. Eu tinha 15 anos. Mas primeiro eu assumi uma homossexualidade que eu fui vendo que não pertencia pra mim. Então, eu comecei minha transição, mas sem referência nenhuma. Não tinha mulher trans em Rio das Flôres, eu só via pela televisão. Foi bem complicado, porque aconteceram vários impedimentos, na escola, para conseguir emprego. Essas complicações eu acho que têm muito a ver com a cidade ser de interior e com a época em que eu transicionei. As pessoas não sabiam o que era isso, ainda mais aí em Rio das Flores. Então, foram várias chacotas, piadinhas (...). A cidade aí é muito complicada. É como se as pessoas achassem naquela época que eu era um homem homossexual. Então eles diziam: Ah, mas você, né? Você não é mulher! (FLORA, 30 anos, junho 2020).

O caso de Flora levanta muitas reflexões acerca da vigilância e disciplinamento dos corpos. Mais do que o comportamento afetivo e sexual, Flora tinha sua identidade de gênero e seu corpo cerceados e sua existência posta em xeque a partir de uma perspectiva de gênero binária e baseada apenas na materialidade do órgão sexual com o qual nasceu, numa tentativa de fixar sua identidade a partir de um regime baseado na sequência sexo-gênero-sexualidade (BUTLER, 1993; LOURO, 2004).

Ela reforça a noção de que no interior o entendimento sobre tais questões é diferente dos grandes centros, enfatizando a inexistência de referentes com as quais pudesse se identificar, o que não ocorreria em grandes centros, já que há 15 anos, em 2005, já havia inúmeras mulheres trans em cidades grandes. A ANTRA (Associação Nacional de Travestis e Transexuais) já havia sido fundada há 05 anos, e o ENTLAIDS (Encontro Nacional de Travestis e Transexuais que Atuam na Prevenção da Aids) já estava em sua XII edição (ANTRA, 2020). A prova de que essas articulações e movimentos sociais de fato não têm representação nas cidades de interior é que, até o momento da escrita deste trabalho, por exemplo, Rio das Flôres e Valença nunca tiveram um representante LGBTQIA+ (de identidade assumida) em um cargo do executivo ou legislativo (TRE, 2020) e Rio das Flôres 


\section{Revista \\ Debates Insubmissos}

especificamente, não conta com nenhum movimento social organizado e nem com Conselho municipal LGBTQIA+.

Dando continuidade à entrevista, apresentamos mais um excerto de fala da participante para posterior análise e reflexão:

(...) Rio das Flôres é uma cidade muito complicada. É uma cidade que eu amo, minha mãe mora aí, tenho amigos aí, mas o preconceito é gigantesco, mas os empedimentos são velados, mas você fica sabendo, porque a cidade é pequena. Como na área de trabalho. Eu fiz muitos cursos, sei que sou capacitada, mas nunca tive oportunidade. Até para trabalhar de costureira numa fábrica aí, foram falar para o dono da fábrica que eu era homossexual, como se isso fosse um adjetivo que desqualificasse alguém. É tipo isso: 'Você vai pegar o currículo dela? Olha, ela é homossexual!Então eu vejo, que em Rio das Flôres, você tem que lutar duas vezes mais, diferente de Volta Redonda quando eu fui morar, mas eu acho que também tem a ver com a passabilidade, que no começo te ajuda, mas depois acaba sendo tóxica. (FLORA, 30, junho 2020).

Apesar de diversos trabalhos apontarem as dificuldades de pessoas trans conseguirem se estabelecer no mercado de trabalho (LEITE JR; REIDEL, 2013; SANTOS, 2017; entre outros), o relato de Flora (assim como o de Juliana) parece indicar que essa abjeção seja mais forte nas cidades de interior pelo fato de que não apenas a/o empregador/a se envolve nessa exclusão, mas as próprias pessoas da comunidade, que já sabem da identidade de gênero divergente da norma e expressa pela candidata, tratam de empreender uma campanha contra sua contratação.

Segundo Fernanda Martinelli, Taya Carneiro e Maria Leo Araruna (2017), o ambiente de trabalho está envolto em barreiras culturais que impossibilitam a entrada e permanência de pessoas trans. Essas pessoas, por sua vez, para tentar garantir seus meios de vida e sobrevivência, acabam por se submeter a uma série de remodelações corporais e subjetivas, no sentido de alcançar aquilo que se nomeia "passabilidade", ou seja, a proximidade física e de expressão de gênero a mulheres ou homens cisgêneras/os, que são consideradas/os na sociedade como expressões do gênero "verdadeiro".

No relato acima, Flora já dá indícios acerca da passabilidade como um "esconderijo", uma fuga dos preconceitos, mas que acaba se tornando uma camisa de força, algo tóxico: 


\section{novist \\ 政}

A passabilidade é tóxica, quando as pessoas ficam sabendo que você é trans, igual aconteceu a pouco tempo agora comigo na faculdade (...) eu me senti liberta, porque você não sabe qual vai ser a reação do outro com você (FLORA, 30, junho 2020).

Ainda sobre os dispositivos que regulam os corpos trans, inserindo-os naquilo que a sociedade convencionou como "natural" ou "verdadeiro", Berenice Bento (2017, p. 324), alega que:

[...] o corpo apresenta-se como uma substância precária que precisa da confirmação e do reconhecimento da feminilidade e masculinidade e que, nesse caso, encontra nas práticas de remodelação, fabricação e consertos dos "defeitos naturais" os dispositivos para tornar-se real. As idealizações de gênero nos levam para lugares inabitáveis, um não lugar, mas que operam ações, opções e desejos. Já nascemos com débitos e teremos a vida inteira para consertar os erros originais.

Conforme a citação da autora, e ainda com base nos relatos de Juliana, do início deste trabalho, todos os corpos são reinseridos neste padrão fixo de feminilidade e masculinidade e aqueles que fogem a tal padrão que se convencionou (histórica, social e arbitrariamente) como aceitável na sociedade, são, a todo o momento, direcionados de volta à norma, por meio de reiterações diárias (BUTLER, 2004). Essa pressão por se aproximar do gênero "verdadeiro", faz com que muitas pessoas trans busquem a passabilidade, mesmo que ela seja dolorosa e imobilizante.

Flora afirma, então, que apesar de suas dificuldades e dúvidas sobre a passabilidade, ainda percebe ser mais fácil sua vida em uma cidade maior:

Mas mesmo assim, eu percebo que em Volta redonda as pessoas são mais abertas. Eu amo, sou apaixonada por Rio das Flôres, mas percebo que é mais complicado. As pessoas se sentem no direito de dar a opinião delas, mas de um lugar em que elas não passam pelo que a gente passa. Já em Volta Redonda, foi muito diferente, eu fiz estágio, meu nome social foi respeitado e no meu estágio eu falei que era uma mulher trans depois da entrevista e eles disseram que não tinha problema nenhum, que o que eles viam era a qualificação da pessoa (...). Fui muito bem recebida e trabalhei por oito meses lá, sem problemas. Foi bem mais tranquilo. Lá é mais cosmopolita e eu acho que isso ajuda (FLORA, 30, junho 2020).

Conforme pode ser percebido pelas falas de Flora e Juliana, pessoas LGBTQIA+ aparentam conseguir emprego mais facilmente fora do âmbito de suas cidades natais, quando se trata de cidades pequenas e de interior e, conforme relatado, os impedimentos à entrada no mercado de trabalho, uma realidade na vida de muitas pessoas no sistema capitalista, são 
ainda mais fortes para pessoas fora dos padrões geralmente aceitos no mercado de trabalho (pessoas brancas, cis e héteros). Essa questão parece ainda mais forte em cidades de interior.

Para finalizar a entrevista, conforme feito com as/os outras/os participantes, pedimos que Flora me informasse sobre as principais diferenças que ela percebeu entre sua cidade natal (cidade pequena e interiorana) e a cidade onde vive hoje, uma cidade bem grande com um grande pólo siderúrgico (Companhia Siderúrgica Nacional - CSN):

Então é isso, morar numa cidade maior te dá uma sensação boa, de maior liberdade, até porque ninguém te conhece, então as pessoas não ficam te chamando pelo nome antigo, igual acontece às vezes em Rio das Flôres. Numa cidade grande, você passeia no shopping num dia e no outro você nem vê as mesmas pessoas, são tantas pessoas que moram na mesma cidade que você não é obrigada a conviver com quem você não tem simpatia. Em Rio das Fôres, não, todas as relações são muito próximas. Mas tem uma coisa, em Rio das Flôres eu me sinto um pouco mais segura com essa coisa de violência. Em Volta Redonda e outras cidades, em relação a isso, eu fico com o pé atrás. Mas eu não tenho nada o que reclamar. Essa é a minha experiência (FLORA,30, junho 2020).

Mais uma vez, corroborando todas as falas das entrevistas anteriores, Flora indica que a maior questão que se coloca com relação a cidades maiores é o medo da violência física.

Ocorre que, mesmo com essa preocupação e todos os casos noticiados de violência e morte de pessoas LGBTQIA+ em grandes centros, essas pessoas ainda conseguem sentir mais liberdade nessas cidades do que no interior e nas cidadezinhas pequenas, onde não há violência física, mas os processos de vigilância e violência simbólica são tão fortes que impelem essas pessoas a saírem de suas cidades, seja definitivamente, ou a passeio, para viverem suas identidades de forma mais livre.

É como se nas cidades de interior a vigilância nunca cessasse, ou conforme explica Foucault (1999, p. 224), haja um panoptismo que impõe às pessoas LGBTQIA+ "um estado consciente e permanente de visibilidade que assegura o funcionamento automático do poder. Fazer com que a vigilância seja permanente em seus efeitos, mesmo se é descontínua em sua ação."

O último entrevistado desta pesquisa é de Valença (RJ). Felipe é um homem trans, de 23 anos, estudante de Direito. Partindo da mesma pergunta feita a todas/os as/os/ 
participantes, Felipe relatou que tanto cidades grandes quanto pequenas exibem pós e contras na vivência de pessoas trans, porém afirmou que:

Nos grandes centros a gente tem mais oportunidade, principalmente no acesso à saúde, que é melhor e mais especializado, com hospitais e ambulatórios que são referência em transexualidade, desde o apoio psicológico até a realização de cirurgia, colocação de prótese, apesar da demanda muito grande (...). Isso a gente não encontra no interior. No interior tudo é muito arcaico ainda. o pensamento das pessoas demora muito a evoluir. Se você procurar por um profissional que te entenda, na maioria das vezes, você não vai encontrar. Ás vezes até encontra, mas é alguém que vai tentar mudar seu pensamento ou vai te usar como cobaia, como experimento, porque ele nunca ouviu falar daquilo antes (FELIPE, 23 anos, junho 2020).

Felipe apresenta uma questão não levantada por outras/os participantes, mas importante para os fins desta pesquisa. Pessoas trans sofrem diversos impedimentos quando buscam atendimento médico, independentemente de este atendimento estar ou não relacionado a processos de cirurgia de redesignação sexual, tomada ou bloqueio de hormônios, ou caso seja para tratar um simples resfriado. São dificuldades relacionadas ao uso do nome social, transfobia, patologização de suas identidades e relação direta e estigmatizante com o HIV/AIDS, entre outras dificuldades (ROCON, et. al, 2016).

O relato de Felipe dá indícios de que no interior tais dificuldades são ainda maiores, pois não há casos de referência e as/os profissionais não têm conhecimento ou experiência na área, de modo que as pessoas trans que procuram por profissionais para atendimentos psicológicos ou ainda endocrinológicos, por exemplo, passarão por um processo de experimentação em que serão utilizados como "cobaias", como indica o relato.

Com relação à violência, Felipe relata a existência de violência tanto nas cidades grandes quanto no interior, mas aponta que nas cidades grandes, esses casos são invisibilizados, e no interior ganham bastante visibilidade:

Quando a gente vê casos de assassinato de pessoas trans no interior, vira um alvoroço, todo mundo busca por justiça por que geralmente todo mundo conhece. Já nos grandes centros, muitas vezes passa despercebido, porque é muita gente. Essas mortes são invisíveis (FELIPE, 23, junho 2020).

Há um ponto a ser colocado sobre o relato de Felipe e que nos leva a pensar. Será o índice de violência contra pessoas LGBTQIA+ menor no interior pelo fato de haver menos 
pessoas com essa identidade? Sabemos pelos marcadores de violência social publicados pelo Instituto de Pesquisa Econômica Aplicada (IPEA) e o Fórum Brasileiro de Segurança Pública (FBSP), que os índices de violência no geral são menores nas cidades de interior (IPEA e FBSP, 2019) por questões diversas como a precarização das condições de trabalho, o tráfico de drogas, a ação violenta da polícia militar, entre diversas outras questões.

O relato de Felipe destoa das/os demais participantes ao dizer que há violência física e risco de morte no interior, fato não relatado pelas/os demais participantes que afirmaram haver mais segurança no interior e em cidades pequenas. Talvez isso possa ser explicado pelo fato de Felipe viver em Valença, uma cidade maior que a das/os outras/os participantes, onde há muito mais habitantes e o índice de violência apesar de muito baixo é bem maior que o de Rio das Flôres.

Sobre assumir e transicionar em contexto de cidade de interior, Felipe relata:

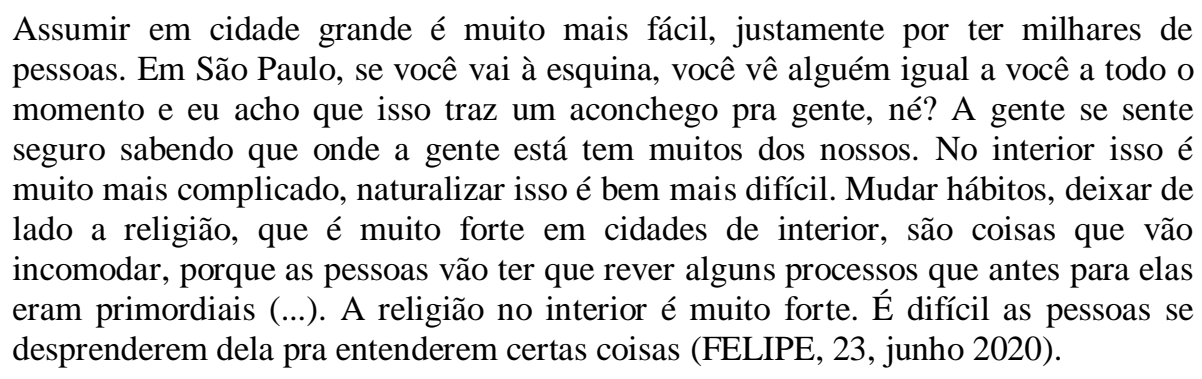

Felipe reitera o que já foi dito nos relatos anteriores e soma a isso o fator religião, que conforme apontam Castro e Ferrari (2017), é capaz de fazer emergir discursos que circulam na sociedade e dizem sobre o que é considerado certo ou errado.

Para finalizar, outro excerto de Felipe será ressaltado, em que diz sobre a resistência de pessoas LGBTQIA+, em todos os lugares:

Eu acho que apesar das diferenças, este processo é muito mais subjetivo que estrutural. Pessoas trans vão encontrar obstáculos em todos os lugares. Mesmo que sejam diferentes, mas vão. Mas a gente tem que resistir né? É pra isso que a gente está vivo: pra resistir! (FELIPE, 23, junho 2020).

É a partir deste relato final de Felipe que finalizamos também este artigo, enfatizando que há ainda muito a se conquistar, muito a se dizer. Foi no sentido de pensar sobre a necessidade de um movimento de união que elucidamos a necessidade de articular mais de 
uma perspectiva teórica neste artigo. Por entender que há processos subjetivos, como relatou Felipe, mas a mudança da sociedade deve se pretender estrutural. Nesse sentido, acreditamos que quanto mais falemos sobre pessoas colocadas à margem, numa perspectiva que considere que as desigualdades se dão de forma consubstancial entre raça, classe e gênero e não separadamente, mais estaremos contribuindo à teoria que deve estar sempre articulada à prática na luta por uma sociedade melhor.

\section{NO RASTRO DOS RELATOS: PALAVRAS FINAIS}

A partir de uma perspectiva de bricolagem entre teorias críticas e pós-críticas, analisamos as falas provenientes de entrevistas de quatro participantes cujas identidades rompem com a cis/heteronormatividade, com o objetivo de compreender como se dão os processos de constituição identitária, trajetórias e vivências dessas pessoas em um contexto de cidades pequenas e/ou de interior.

Reiteramos que as vivências em tais cidades são marcadas por processos de vigilância e disciplinamento dos corpos, principalmente pelo fato de todas as vidas serem públicas, uma vez que "todo mundo se conhece". Esse é um dos marcadores importantes relatados pelas/os participantes desta pesquisa. Assumir a própria identidade neste contexto torna-se muito difícil, porque vai além de uma questão pessoal ou familiar. Trata-se de um "sair do armário" coletivo, pois todas as pessoas participam dele, geralmente com olhares de julgamento. Nesse sentido, as/os participantes relatam a necessidade de sair de sua cidade natal para viver sua sexualidade ou a sua identidade de gênero de maneira mais livre e, ainda, para conseguir um lugar no mercado de trabalho, espaço também interdito nas cidades de interior com mais força que nos grandes centros, conforme pode-se depreender das falas analisadas.

Outro fator que nos chamou atenção foi o fato de que a principal apreensão com relação aos grandes centros foi a violência física e o risco de vida. Ainda assim, as/os entrevistadas/os relataram conseguir viver com mais liberdade nas cidades maiores. o 
Destacamos, ainda, a precariedade nos atendimentos de saúde nas cidades pequenas e/ou de interior para pessoas LGBTQIA+, principalmente para pessoas trans, que não encontram aqui as possibilidades de tratamento endocrinológico, psicológico ou de cirurgia de redesignação sexual. Por fim, chamamos a atenção para a forte influência religiosa, uma vez que, em pequenas cidades, ainda há uma apego maior às tradições, ideologias e festividades religiosas influenciando amplamente no processo de construção da vida social das pessoas.

Terminamos essas reflexões ressaltando a necessidade de maiores pesquisas sobre tal temática dada a escassa produção existente sobre o tema e os resultados obtidos nesta pesquisa, que indicam haver fortes dimensões de vigilância e violência simbólica nas cidades de interior, que acabam compelindo pessoas LGBTQIA+ ao abandono de suas famílias ou a viver sua sexualidade e/ou identidade de gênero em constante disciplinamento.

\section{REFERÊNCIAS}

ABREU, Maira; CASTRO, Bárbara. Marxismos, feminismos, queer e sexualidades: Parte I.

Crítica Marxista, n.48, p.89-107, 2019. Disponível em:

https://www.ifch.unicamp.br/criticamarxista/arquivos_biblioteca/dossie2019_11_18_15_59_5 5.pdf Acesso em 22 jun 2020.

ANTRA. ASSOCIAÇÃO NACIONAL DE TRAVESTIS E TRANSEXUAIS. História. 2020. Disponível em: https://antrabrasil.org/historia/ Acesso em 20 jun 2020.

BENEDETTI, Marcos. Toda Feita: o corpo e o gênero das travestis. Rio de Janeiro: Garamond, 2005. 144 p.

BORTOLETTO, Guilherme Engelman. LGBTQIA+: identidade e alteridade na comunidade. 2019. 32f. Trabalho de Conclusão de Curso. Pós-graduação em Gestão de Produção Cultural. Universidade de São Paulo, São Paulo, 2019.

BRASIL. MINISTÉRIO DA EDUCAÇÃO.Secretaria Especial de Políticas para as Mulheres (SPM/PR) Secretaria Especial de Políticas de Igualdade Racial (SEPPIR/PR). Gênero e diversidade na escola: formação de professoras/es em Gênero, Orientação Sexual e Relações Étnico-Raciais. Livro de conteúdo. Versão 2009. - Rio de Janeiro: CEPESC; Brasília: SPM, 2009.

BUTLER. Judith. Bodies that matter. On the Discursive Limits of "Sex". New York: 
Routledge, 1993.

BUTLER, Judith. Undoing Gender. New York: Routledge, 2004, 288 p.

CASTRO, Roney Polato de; FERRARI, Anderson. A "ideologia de gênero" e os processos educativos nos discursos religiosos: efeitos de saber-poder-verdade. In: FERRARI, Anderson; CASTRO, Roney Polato de (Orgs). Diversidades sexuais e de gêneros: desafios e potencialidades de um campo de pesquisa e conhecimento. Campinas, SP: Pontes Editores, 2017. p. $75-100$

EAGLETON, Terry. Ideologia. São Paulo: Boitempo, $19971^{\text {a }}$ ed. 2002.

ENNES, Marcelo Alario; MARCON, Frank. Das identidades aos processos identitários: repensando conexões entre cultura e poder. Sociologias, Porto Alegre, ano 16, no 35, jan/abr 2014, p. 274-305. Disponível em: https://www.scielo.br/pdf/soc/v16n35/a10v16n35.pdf Acesso em 24 jun 2020.

INSTITUTO DE PESQUISA ECONÔMICA APLICADA; FÓRUM BRASILEIRO DE SEGURANÇA PÚBLICA. Atlas da violência 2019. 2019. Disponível em:

https://www.ipea.gov.br/portal/images/stories/PDFs/relatorio_institucional/190605_atlas_da violencia_2019.pdf Acesso em 26 jun 2019.

FALQUET, Jules. A combinatória straight. Raça, classe, sexo e economia política: análises materialistas e decoloniais. Crítica Marxista, n.48, p.127-145, 2019.Disponível em: https://www.ifch.unicamp.br/criticamarxista/arquivos_biblioteca/dossie2019_11_18_16_05_1 8.pdf Acesso em 22 jun 2020.

FERRARI, Anderson.; COUTO; José Gabriel de Viveiros Barbosa. Homossexualidades masculinas e cidade pequena. Bagoas - Estudos gays: gêneros e sexualidades, v. 8, n. 11, 11. Disponível em: https://periodicos.ufrn.br/bagoas/article/view/6550 Acesso em 23 jun 2020.

FOUCAULT, Michel. História da sexualidade I: A vontade de saber. Tradução de Maria Thereza da Costa Albuquerque e J. A. Guilhon Albuquerque. Rio de Janeiro, Edições Graal, 1988.

FOUCAULT, Michel. Vigiar e punir. 20. ed. Petrópolis: Vozes, 1999.

FRANCO, Neil. Entre as fronteiras do gênero e das sexualidades: professoras travestis, transexuais e transgêneros brasileiras. Juiz de Fora : Editora UFJF, 2019.

HEILBORN, Maria Luiza (org). Família e sexualidade. Rio de Janeiro: Editora FGV, 2004. IBGE. Instituto Brasileiro de Geografia e estatísticas. Rio das Flôres. 2017. Disponível em: https://cidades.ibge.gov.br/brasil/rj/rio-das-flores/panorama Acesso em 23 jun 2020. 
IBGE. Instituto Brasileiro de Geografia e estatísticas. Valença. 2017. Disponível em: https://cidades.ibge.gov.br/brasil/rj/valenca/panorama Acesso em 23 jun 2020.

KINCHELOE, Joe L. Redefinindo e Interpretando o Objeto de Estudo. In: KINCHELOE, Joe L.; BERRY, Kathlenn S. Pesquisa em Educação: conceituando a bricolagem. Tradução de Roberto Cataldo Costa. Porto Alegre: Artmed, 2007. P. 101-122.

LANZ, Letícia .O corpo da roupa: a pessoa transgênera entre a transgressão e a conformidade com as normas de gênero. Curitiba, 2014. 342 f. Dissertação (Mestrado em Sociologia). Setor de Ciências Humanas da Universidade Federal do Paraná: 2014.

LEITE JÚNIOR, Jorge. Nossos corpos também mudam: a invenção das categorias "travesti" e "transexual" no discurso científico. São Paulo, Annablume, FAPESP, 2011.

LOPES, João Teixeira. Em busca de um lugar no mapa: reflexões sobre políticas culturais em cidades de pequena dimensão. Sociologia, Problemas e Práticas, Oeiras, n. 34, p. 81-91, dez. 2000 . Disponível em <http://www.scielo.mec.pt/scielo.php?script=sci_arttext\&pid=S0873$65292000000300004 \& \operatorname{lng}=$ pt\&nrm=iso $>$. acesso em 24 jun. 2020.

LOURO, Guacira Lopes. Gênero, sexualidade e educação: uma perspectiva pósestruturalista. Rio de Janeiro: Vozes, 1997.

LOURO, Guacira Lopes. Um corpo estranho: ensaios sobre sexualidade e teoria Queer. Belo Horizonte: América, 2004.

MARTINELLI, Fernanda; CARNEIRO, Taya, ARARUNA, Maria Léo Araruna. "Agora eu sou passável": discriminação e negociações para acesso ao mundo do trabalho por pessoas trans. $3^{\mathbf{0}}$ Seminário Internacional Desfazendo Gênero. Campina Grande, Paraíba, 2017. Disponível em:

https://www.academia.edu/35161226/_AGORA_EU_SOU_PASS\%C3\%81VEL_DISCRIMI NA\%C3\%87\%C3\%830_E_NEGOCIA\%C3\%87\%C3\%95ES_PARA_ACESSO_AO_MUND O_DO_TRABALHO_POR_PESSOAS_TRANS?auto=download Acesso em 25 jun 2020.

MISKOLCI, Richard. Teoria queer: um aprendizado pelas diferenças. 2. ed. rev. e aum. Belo Horizonte: UFOP (Universidade Federal de Ouro Preto), 2012. 82 p.

PIÑEROS, Théo Lobarinhas. Valença: dos caminhos de comércio à indústria. Cadernos do desenvolvimento Fluminense, n.6, 2015. Disponível em: https://www.epublicacoes.uerj.br/index.php/cdf/article/view/17738 Acesso em 24 jun 2020.

RIO DE JANEIRO. TRIBUNAL DE CONTAS DO ESTADO. SECRETARIA DE PLANEJAMENTO. Estudos Socioeconômicos dos municípios fluminenses: Rio das Flôres.2011. Disponível em: http://www.cedca.rj.gov.br/pdf/riodasflores.pdf Acesso em 23 
jun 2020 .

ROCON, P. C. et al. Dificuldades vividas por pessoas trans no acesso ao Sistema Único de Saúde. Ciência \& Saúde Coletiva, v. 21, n. 8, p. 2517-2525, 2016.Disponível em https://www.scielo.br/pdf/csc/v21n8/1413-8123-csc-21-08-2517.pdf Acesso em 26 jun 2020.

SAFFIOTI, Heleieth. A mulher na sociedade de classes. 3. ed. São Paulo: Expressão Popular, 2013.

SANTOS, Dayana Brunetto Carlin dos. Docências trans*: entre a decência e a abjeção. 2018. 445f. Tese (Doutorado em Educação) Doutorado, Universidade Federal do Paraná, Curitiba, 2017.

SEDGWICK, Eve Kosofsky. A epistemologia do armário. Cadernos Pagu n.28, janeirojunho de 2007. Disponível em:

https://repositorio.ufsc.br/bitstream/handle/123456789/3503/sedgwickeve.pdf?sequence=1\&isAllowed=y Acesso em 24 jun 2020.

SILVA, Annibal Affonso Magalhães da. Bens Culturais Imóveis: Logradouros Urbanos e Rurais do Município de Rio das Flores. Rio das Flores, edição do autor, 2013.

SILVA, Tomaz Tadeu da. Desconstruindo o construtivismo pedagógico. Educação e Realidade, Porto Alegre, v. 18, n.2, p.3-10, jul./dez. 1993.

SILVA, Tomaz Tadeu da. Identidade e diferença: a perspectiva dos estudos culturais. Tomaz Tadeu da Silva (org.), Stuart Hall, Kathryn Woodward. Petrópolis, RJ: Vozes, 2000. SOF - SEMPREVIVA ORGANIZAÇÃO FEMINISTA. Reação patriarcal contra a vida das mulheres: debates feministas sobre conservadorismo, corpo e trabalho. 2016. Disponível em: https://www.ufsj.edu.br/portal2-repositorio/File/centrocultural/Cartilha-Sof(1).pdf Acesso em 25 jun 2020.

SPOSITO, Maria Encarnação Beltrão. A questão cidade-campo: perspectivas a partir da cidade. In: SPOSITO, M. E. B.; WHITACKER, A. M. (Org.). Cidade e campo: relações e contradições entre urbano e rural. 2. ed. São Paulo: Expressão Popular, 2010. p. 111-130. TRE RJ. Tribunal Regional Eleitoral do Estado do rio de Janeiro. Resultado de votação: candidatos por município. Disponível em: https://www.trerj.jus.br/site/eleicoes/index.jsp?vmenu=2012/resultados/municipio/municipio.jsp\&pag=1\&vm enu_aux=2012\# Acesso em 25 jun 2020.

VINUTO, Juliana. A amostragem em bola de neve na pesquisa qualitativa: um debate em aberto. Revista Temáticas, Campinas, v. 22, n.44, p. 203-220, ago/dez. 2014. Disponível em: https://econtents.bc.unicamp.br/inpec/index.php/tematicas/article/download/10977/6250 
Revista

Debates Insubmissos

Acesso em 22 jun 2020

Submetido em: $29 / 06 / 2020$

Aprovado em: 16/07/2020 